\title{
Changes in respiratory function following the intramuscular administration of etorphine to boer goats (Capra hircus)
}

\author{
P E Buss ${ }^{a}$ and D G A Meltzer ${ }^{b}$
}

\begin{abstract}
The physiological effects on respiratory function of etorphine (M99, Logos Agvet) $(30 \mu \mathrm{g} / \mathrm{kg})$ administered intramuscularly were determined in boer goats. The goats were habituated to the experimental procedures so that respiratory function could be determined while the animals stood quietly at rest. This enabled the physiological changes induced by etorphine to be measured and compared with those obtained before administration of theimmobilising drug. The effectiveness of diprenorphine(M5050, Logos Agvet) ( $3 \mathrm{mg} / \mathrm{l} \mathrm{mg}$ etorphine) as an antagonist of the physiological changes induced by the etorphine treatment was also determined. Etorphine depressed respiratory function, which resulted in a decreasein $\mathrm{PaO}_{2}$ and an increasein $\mathrm{PaCO}_{2}$. Thesechanges werelimited and occurred as a result of decreases in respiratory minute volume and alveolar minute ventilation caused by a decrease in respiratory rate. The physiological shunt fraction did not change significantly but there was a significant decrease in percentage physiological dead space ventilation. It was not possible to determine how effectively diprenorphine reversed the respiratory effects due to etorphine.
\end{abstract}

Key words: Capra hircus, diprenorphine, etorphine, goats, respiratory function.

Buss P E, Meltzer D G A Changes in respiratory function following the intramuscular administration of etorphine to boer goats (Capra hircus). Journal of the South African Veterinary Association (2001) 72(3): 137-142 (En.). Department of Companion Animal Surgery, Faculty of Veterinary Science, University of Pretoria, Private Bag X04, Onderstepoort, 0110 South Africa.

\section{INTRODUCTION}

Etorphine, often in combination with either a sedative or tranquilliser, has been used extensively in the immobilisation and capture of African ungulates ${ }^{10,26}$. Nevertheless, very little is known about the physiological responses of non-domestic artiodactyls either to these procedures or to the drug ${ }^{6}$. In most studies respiratory function has only been monitored once theanimalshavebeen immobilised. Thus, baseline data and physiological changes during the critical induction period are unknown . It is also difficult to differentiate between the drug-induced effects and the concurrent physiological effects due to capture and handling ${ }^{12}$.

Etorphine acts stereospecifically with opioid receptors, inducing a conformational change, which in turn results in biochemical changes within the neuron $^{3,23}$. Etorphineactsasan agonist at both mu- and kappa-receptors. Thisresultsin a number of effects, induding supraspinal

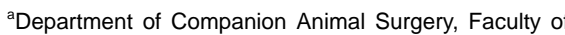
Veterinary Science, University of Pretoria, Private Bag X04, Onderstepoort, 0110 South Africa.

${ }^{\mathrm{b}}$ Alexander Forbes Chair of Wildlife Diseases, Faculty of Veterinary Science, University of Pretoria, Private Bag X04, Onderstepoort, 0110 South Africa.

Received: October 2000. Accepted: June 2001. and spinal analgesia, euphoria, sedation and respiratory depression ${ }^{23}$. Respiratory depression dueto etorphineappearsto be mediated by the $\mathrm{mu}_{2}$-receptors ${ }^{4}$, and is primarily due to a direct effect on the brainstem respiratory centres, reducing their responsiveness to carbon dioxide. Etorphinealso depresses the pontineand medullary centres that regulate respiratory rhythm and the responsiveness of the medullary respiratory centres to electrical stimulation. Large numbers of opioid receptors are found in the medullary areas believed to be important in ventilatory control ${ }^{13}$.

Diprenorphine is classified as a mixed antagonist, retaining some agonistic activity. As its action is much closer to that of an antagonist, it is routinely used as a reversing agent for etorphine ${ }^{16,26}$. Diprenorphine can be administered intravenously or intramuscularly. If given intramuscularly it is reported to take 5 to 10 minutes to reverse the effects of etorphine, compared to a few seconds to 4 minutes if given intravenously ${ }^{1}$.

Domestic goats have been used in experiments to evaluate the effects of etorphine on some respiratory and cardiovascular functions ${ }^{11,27}$. Goats were selected for thisstudy, as they can bemore easily handled under experimental conditions, are relatively small and are easily tamed. As a result, they are less likely to manifest restraint-induced physiological changes. Studies to date suggest that the goat is a suitable model to determine the physiological effects of drugs commonly used in the immobilisation of non-domestic artiodactyls $\mathrm{s}^{11,12,18,27}$.

We report here on part of a more extensive study that not only examined the effects of etorphine on respiratory function, but also recorded the effects of etorphine and etorphine combined with xylazine or azaperone on respiratory and cardiovascular function in goats.

The aims of the study were to:

- evaluatethe effects on respiratory function of etorphinefollowing intramuscular administration,

- evaluate the antagonist diprenorphine in its ability to reverse the effects on respiratory function induced by etorphine,

- measure baseline data under controlled conditions, from which the effects of etorphine in goats can be used to estimate the effects it may have in nondomestic artiodactyls.

\section{MATERIALS AND METHODS}

\section{Animals}

Eight non-pregnant female boer goats of a similar age and body mass were kept together in an enclosure. They were fed lucerneand concentratepelletsand water was provided ad libitum. Six animals from this herd were assigned to be used in the research procedures and 2 were kept as replacements to be used in the event of any losses. Before commencement of the study, each animal was examined clinically, and haematological and blood chemistry profiles were measured. Each goat was treated at the time of the clinical examination with $1 \mathrm{ml}$ Ivermectin $1 \%$ $\mathrm{m} / \mathrm{v}$ (Ivomec injectable, Logos Agvet), administered subcutaneously. During the period of confinement, faecal flotations were performed from time to time on fresh samples collected randomly from the enclosure in which the goats were housed. 
To prevent the goats from becoming unduly distressed or excited, they were habituated to standing on a low research table while restrained by their horns during the following procedures: being handled, insertion of arterial and venous catheters, and the attachment of various other measuring devices. They were also conditioned to breathe into an attached face mask so that expired air samples could be collected.

\section{Carotid relocation}

About 2 months before the start of the trial, the left carotid artery of each goat was relocated surgically to a subcutane ous position in the neck to facilitate the collection of arterial blood samples, using the technique described by Butler ${ }^{5}$.

\section{Preparation of trial procedures}

Onetrial wasdoneper day, in themorning. Food was withheld from the single selected animal for 17 hours and water for 2 hours beforeto thestart of each trial. The goat was weighed. The neck was shaved on either side from immediately below the mandible to the level of the thoracic inlet. Long-acting penicillin (Peni L A Phenix, Logos Agvet) was administered intramuscularly.

The goat was placed standing on the research table, fastened to an overhead bar by a nylon rope tied around the base of its horns. An airtight face mask was placed over the nostrils and fixed in place with a crepe bandage. The animal was blindfolded, its ears were plugged with cotton wool, and the pinnae were folded back out of the way and fixed to the horns with adhesive tape. Electrocardiogram (ECG) leads were attached to prepared sites on the lateral surfaces of the legs, above the carpi and hocks. The ECG waveform wasused primarily to monitor cardiac function during the insertion of the thermodilution catheter and during the trial. A thermometer probe was placed $10 \mathrm{~cm}$ into the rectum and fastened to the base of the tail with adhesive tape.

\section{Catheterisation for blood-gas samples}

Local anaesthetic (Lignocaine injection $2 \%$, Bayer Animal Health) was injected subcutaneously at a site above the translocated carotid artery and over the jugular vein on the opposite side of the neck. After a skin incision had been made at each site an arterial catheter (20G Radial Artery Catheterization Set, Arrow Africa) was inserted into the translocated carotid artery and a percutaneous sheath introducer for the thermodilution catheter (Percutaneous Sheath Introducer Set with Side Port/Hemostasis Valve, Arrow
Africa) was inserted into the right jugular vein under aseptic conditions. Both were sutured to the skin to keep them in place. A thermodilution catheter (7French gauge, Infusion port five lumen thermodilution catheter, Arrow Africa) was inserted through the percutaneous sheath introducer into the jugular vein and passed down through theright ventricleand into the pulmonary artery. The route taken by the catheter and progress of its insertion was monitored by viewing changes in blood pressure that took place in the jugular vein, right atrium, right ventricle and pulmonary artery on the screen of the vital signs monitor (DINAMAP ${ }^{\mathrm{TM}}$ PLUS Vital Signs Monitor Model 8720 plus Printer Module, CRITIKON, Johnson \& Johnson) attached to it. The position of the end of the catheter in the pulmonary artery was standardised by inserting it with the balloon inflated until a wedge pressure was recorded. The balloon was then deflated. Once a goat had been prepared it was left to stand quietly for 10 minutes before the start of each trial.

\section{Sampling}

During the trial, samples and data were collected at 10-minute intervals, starting 25 minutes before injection of etorphine. Theseincluded mixed venous and arterial blood samples, expired and end-tidal (alveolar) air, respiratory rate and body temperature. These data were collected on 3 occasions before drug administration.

\section{Blood-gas samples}

The arterial blood sample was collected from the intra-arterial catheter in the carotid artery. A mixed venous blood sample was collected from the pulmonary artery using the distal lumen of the thermodilution catheter. All samples were collected anaerobically into heparin-treated glass syringes. The syringe was immediately capped, placed in an ice-bath and processed within $10 \mathrm{~min}$ utes. Both the arterial and mixed venous blood samples were analysed in a bloodgasapparatus (ABL 500, Medical Distributors Ltd).

\section{Expired air}

Expired air was collected over a period of 3 minutes through a 1-way valve from the face mask into in a $200 \mathrm{gm}$ meteorological balloon (Totex Meteorological balloon, C.W. Price and Company). During collection of the expired air the respiration rate was counted. Immediately following the collection of the expired air, the balloon was sealed and a $50 \mathrm{ml}$ mixed expired gas sample was collected from the neck of the balloon into a glass syringe. This sample was processed in the blood-gas apparatus. The volume of expired air remaining in theballoon wasmeasured in aspirometer. The temperature of the spirometer was recorded at the same time.

\section{End-tidal air samples}

Theposition of the trachea was palpated at thethoracicinlet and theoverlying skin was marked with a black permanent marker on the tracheal midline. This site wasinfiltrated with $3 \mathrm{ml}$ of $2 \%$ lignocaine. During the trial, a $1.2 \times 38 \mathrm{~mm}$ hypodermic needle was inserted into the trachea at this site and end-tidal air samples were collected into a $50 \mathrm{ml}$ glass syringe. The samples were immediately analysed in the blood-gas apparatus.

\section{Drugs administered}

Etorphine $(30 \mu \mathrm{g} / \mathrm{kg})$ was administered by deep intramuscular injection at time 0 minutes. The total volume of etorphine injectable solution was standardised at $2 \mathrm{ml}$ using sterile water. A standard injection site $5 \mathrm{~cm}$ behind the wing of theilium into the gluteal muscle on the right side of the animal was used. Each goat was considered to be immobilised when it assumed sternal recumbency and no longer responded to a painful stimulus caused by application of artery forceps across a coronary band. Diprenorphine ( $3 \mathrm{mg} / 1 \mathrm{mg}$ etorphine) was administered intravenously 40 minutes after drug administration (PDA), i.e., after administration of theetorphine. All trialsended at 95 minutes PDA.

\section{Calculation of derived variables}

Respiratory minute volume BTPS $_{\text {TP }}$

The respiratory minute volume was assumed to be equivalent to the expired volume of air per minute. The volume of expired air was measured in a spirometer at ambient temperature, pressure and saturated with water vapour (ATPS). The volume at body temperature, ambient pressureand saturated with water vapour (BTPS) was calculated using standard formulae ${ }^{30}$. All respiratory volumes measured at ATPS were reported and discussed at BTPS.

\section{Tidal volume BTPS $_{\text {Ti }}$}

The respiratory minute volume was divided by the respiratory rate to givethe tidal volume?.

\section{Alveolar minute ventilation ${ }_{\text {BTPS }}$}

Alveolar ventilation is equivalent to tidal volume minus the dead space ventilation $^{32}$. Dead spaceventilation wascalculated using the partial pressures of carbon 
dioxide in the arterial blood and mixed expired air samples ${ }^{32}$. All volumes were measured atATPS and converted to BTPS.

\section{Physiological shunt fraction}

The physiological shunt fraction expressed as a percentage of the cardiac output was calculated using the standard formula as reported by West ${ }^{29}$. 'I deal oxygen saturation' and thus 'ideal oxygen concentration of the end capillary blood' was calculated using the algorithm re ported by Watney ${ }^{28}$. No algorithm was availablefor goats. Thealgorithmindicated for sheep was found to be unsuitable for goats, as negative physiological shunt fractions resulted. The algorithm and constants indicated for cattle were there fore used ${ }^{28}$.

Physiological dead space ventilation fraction

Physiological dead space ventilation was calculated and expressed as a percentage of the tidal volume ${ }^{29}$.

\section{Statistical analysis}

Statistical analysis of the collated data was performed using the Statistical Analysis System (SAS ${ }^{\circledR}$, SAS Institute SA, Houghton). As the data were unbalanced owing to some missing observations, statistical analysis was performed using General Linear Models (GLM).

The dependent variable used was the variable determined for each timeinterval for the physiological variables examined (e.g. $\mathrm{PaO}_{2}$, alveolar minute ventilation, etc.) for etorphine, i.e. within the drug. These included variables between the mean baseline value at rest (MBVR) and variables measured at any subsequent time interval. The class variable had 1 level, i.e. etorphine.

The covariable was the mean of the 3 values measured at $-15,-10$ and $-5 \mathrm{~min}$. when the goats were standing at rest, ie. MBVR. In developing the GLM the square of MBVR (SQMBVR) was initially included as a second covariable to ensure that the relationship between MBVR and the dependent variable was linear and not a quadratic. As the relationship was found to belinear, SQMBVR wasnot used in the final model.

The GLM performed an initial F-test to determine whether the model provided a significant fit to the data. The covariable, as stated above, accounted for variation between the goats. Subsequently, a Fischer's test was used for pairwise comparisons between time intervals within treatments. The probability value for significance was set at $P \leq 0.05$. Data are presented graphically as the mean plus standard error (SE) (Figs 1-6).

\section{RESULTS}

\section{Immobilisation}

All goats became immobile within 5 minutes of drug administration. They went down into asternal position and did not respond to painful stimuli. Administration of diprenorphine was followed by a brief period of increased activity in the goats during which they often defaecated and urinated. Thereafter they settled into a sternal position once again and appeared to bepartially sedated although aware of their surroundings.

\section{Blood gases and respiratory function}

The $\mathrm{PaO}_{2}$ decreased significantly and reached a minimum value 5 minutes after administration of etorphine. It then gradually increased until diprenorphine was given. These changes were mirrored by a rapid and significant rise in the $\mathrm{PaCO}_{2}$ followed by a gradual decrease (Fig. 1). However, the $\mathrm{PaCO}_{2}$ returned to its baseline value after 35 minutes. The arterial $\mathrm{pH}$ declined rapidly during the initial 5 minutes, and then underwent a gradual return to the baseline value during the remaining period of immobilisation (Fig. 2). Respiratory minute volume and alveolar minute ventilation both decreased significantly and reached minimum values 15 minutes after etorphine administration (Figs 3, 5). The decrease in respiratory minutevolumewasaccompanied by significant changes in respiratory rate rather than in tidal volume (Fig. 4). The respiratory minute volume and alveolar minute ventilation increased over time until the diprenorphine was administered.

Thephysiological shunt fraction did not change significantly during the period of immobilisation. The percentage physiological dead space ventilation decreased significantly within 5 minutes of drug administration and did not changethereafter until the diprenorphine was administered (Fig. 6).

The administration of diprenorphine was followed by a return of the $\mathrm{PaO}_{2}$ and arterial $\mathrm{pH}$ values to their respective baseline values (Figs 1, 2). There was an immediate, although temporary, rise in the respiratory minute volume, with increases in both respiratory rate and tidal volume (Figs 3, 4). The alveolar minute ventilation returned to its baseline value within 5 minutes and subsequently did not change significantly (Fig. 5). The physiological dead space ventilation fraction, despite an initial increase for 20 minutes, remained significantly lower than its baselinevalue until theend of the trial (Fig. 6).

\section{DISCUSSION}

Thesignificant decrease in the $\mathrm{PaO}_{2}$ and increase in the $\mathrm{PaCO}_{2}$ within 5 minutes of administration of the etorphine was not unexpected. Similar results have been reported when goats were administered $0.04 \mathrm{mg} / \mathrm{kg}$ of etorphine intramuscularly ${ }^{12}$. The decrease in $\mathrm{PaO}_{2}$ and increase in $\mathrm{PaCO}_{2}$ followed significant decreases in respiratory minute volume and alveolar minute ventilation, which were the result of a decrease in respiratory rate rather than a change in tidal volume. The percentage physiological shunt did not changesignificantly and thereforedid not contribute to the changes observed in the blood gases. During the same period, the percentage physiological dead space ventilation decreased and could be expected to have resulted in an increase in $\mathrm{PaO}_{2}$ and a decrease in $\mathrm{PaCO}_{2}$.

Respiratory depression is reported to be the principal toxic effect of the opioids in immobilised animals, with sensitivity to the drugs varying between species and individuals within species. It may result in severe hypoxia, hypercapnoea and progressive acidosis ${ }^{9,26}$. Respiratory depression has been reported in Equidae, including the Mongolian horse (Equus przewalskii), and Grevy's zebra (Equus grevyi) ${ }^{1}$. It has also been reported in domestic cattle (Bos taurus) and bighorn sheep (0 vis canadensis) $)^{1}$, bears ${ }^{10}$ and the monkey, dog, cat and rat $^{2}$.

Impala immobilised with the opioids A-3080 $(80.7 \mu \mathrm{g} / \mathrm{kg})$ or carfentanil $(68.8 \mu \mathrm{g} / \mathrm{kg})$ administered intramuscularly, developed apparent hypoventilation soon after immobilisation, based on measurements of respiration rate, relative oxygen saturation and total serum carbon dioxide $^{14}$. The respiratory volumes were not measured. Immobilisation of scimitarhorned oryx (O ryx dammah) with etorphine in combination with acepromazine or xylazine resulted in a fall in arterial oxygen tension, mild hypoxaemia and hypercapnoea, but did not cause respiratory acidosis ${ }^{21}$.

Immobilisation of adult Saanen goats with etorphine $(70 \mu \mathrm{g} / \mathrm{kg})$ and acepromazine $(0.2 \mathrm{mg} / \mathrm{kg})$ is reported to cause a decrease in respiratory rate and an increase in airway resistance. This was attributed to a decrease in lung volume due to the animals assuming sternal recumbency ${ }^{18}$. Intramuscular administration of etorphine in domestic goats premedicated with either triflupromazine or triflupromazine and atropine resulted in a decrease in respiratory rate ${ }^{27}$. Etorphine $(20 \mu \mathrm{g} / \mathrm{kg})$ given intravenously to adult mixed-breed goats produced a significant bradypnoea with maximum depression occurring at 2.5 minutes after administra- 
tion. Thereafter, respiratory rates gradually increased, returning to normal within 45 minutes $^{11}$.

Etorphine has an inhibitory effect on the brain stem respiratory centres, reducing their sensitivity to carbon dioxide and results in a decreased respiratory drive $^{13,23}$. Although opioids are reported to depress all phases of respiration, their primary effect is a reduction of the rate of breathing ${ }^{13}$, as was recorded in this investigation (Fig. 4). Heard et al ${ }^{11}$ reported that goats injected with etorphine intravenously developed a significant bradypnoea. Etorphine administered to goats premedicated with either triflupromazine or triflupromazine and atropine, resulted in a decrease in respiratory rate $^{27}$. Similar results are reported in Saanen goats given etorphineplusacepromazine ${ }^{18}$. Tidal volume, respiratory minute volume and alveolar minute ventilation were not measured in these studies.

Therespiratory volumes in theimmobilised goats may also have been depressed by a number of factors other than inhibition of the respiratory centres by etorphine. These include: a change in body position from standing to sternal recumbency, obstruction of the upper airway resulting in an increased resistance to airflow $^{17,31}$, or development of ruminal bloat $^{17}$.

There is a reported rise in intraruminal and intraperitoneal pressure in cattle that assume sternal recumbency, which changes the relative position of the diaphragm, resulting in an increase in respiratory resistance ${ }^{25}$. Increased measured airway resistance was reported when goats assumed sternal recumbency after immobilisation with etorphine and acepromazine ${ }^{18}$.

The effects that the change in body position had on respiratory function in this investigation were not determined. The goats assumed sternal recumbency after administration of etorphine, and this position was maintained in all the immobilised animals. There were no differences in the postural changes that occurred and thus the effects on respiratory function were similar in all cases.

The heads of the goats were supported in an elevated position and the same relative positions of the head, neck and thorax were maintained throughout each trial period. No significant change in airway resistance could have occurred ${ }^{15}$. Maintaining the head and neck position also allowed unobstructed passage of gas produced in the rumen and prevented development of ruminal bloat.

The initial etorphine-induced depression of respiratory function in the immo-

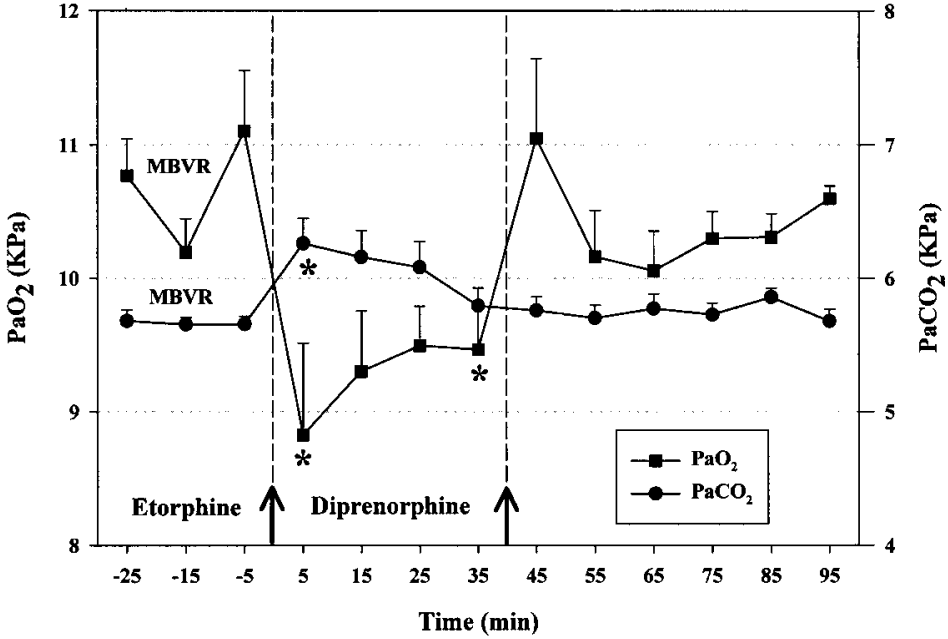

Fig. 1: Mean arterial $\mathrm{PaO}_{2}$ and $\mathrm{PaCO}_{2}$ in goats treated with etorphine. Error bar $=1 \mathrm{SE}$. MBVR = mean baseline value at rest. Asterisks indicate statistically significant differences $(P \leq 0.05)$ between MBVR and the signalled mean value. Arrows indicate times at which etorphine and diprenorphine were injected.

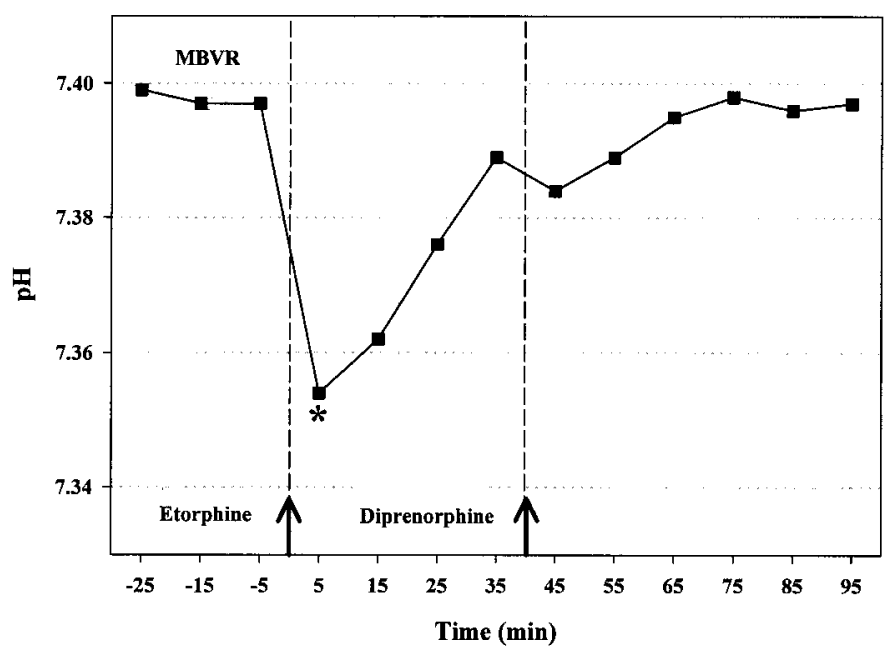

Fig. 2: Mean arterial pH in goats treated with etorphine. $M B V R=$ mean baseline value at rest. The asterisk indicates a statistically significant difference $(P \leq 0.05)$ between MBVR and the signalled mean value. Arrows indicate times at which etorphine and diprenorphine were injected.

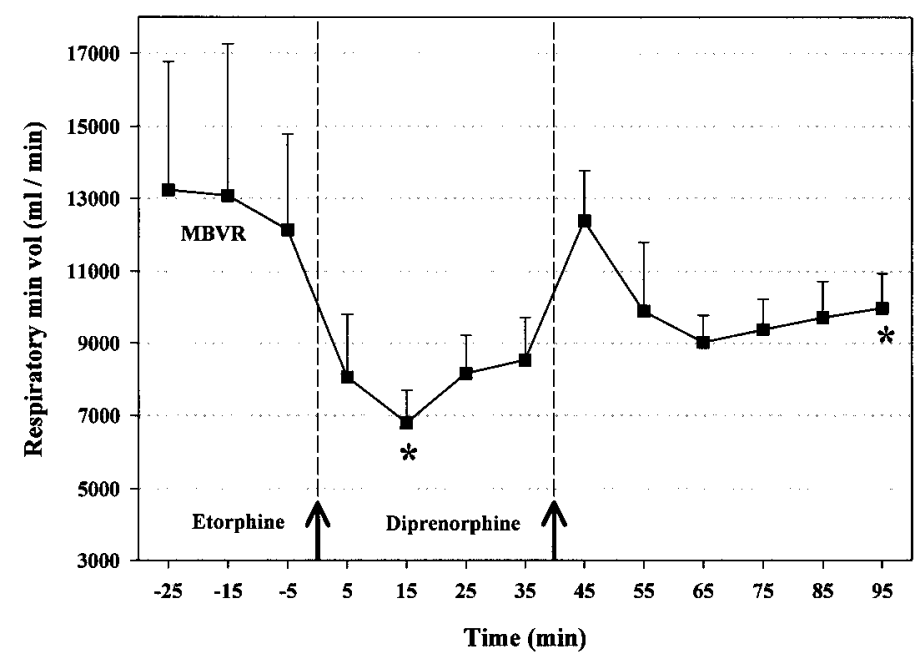

Fig. 3: Mean respiratory minute volume in goats treated with etorphine. Error bar $=1 \mathrm{SE}$. MBVR = mean baseline value at rest. Asterisks indicate statistically significant differences $(P \leq 0.05)$ between MBVR and the signalled mean value. Arrows indicate times at which etorphine and diprenorphine were injected. 


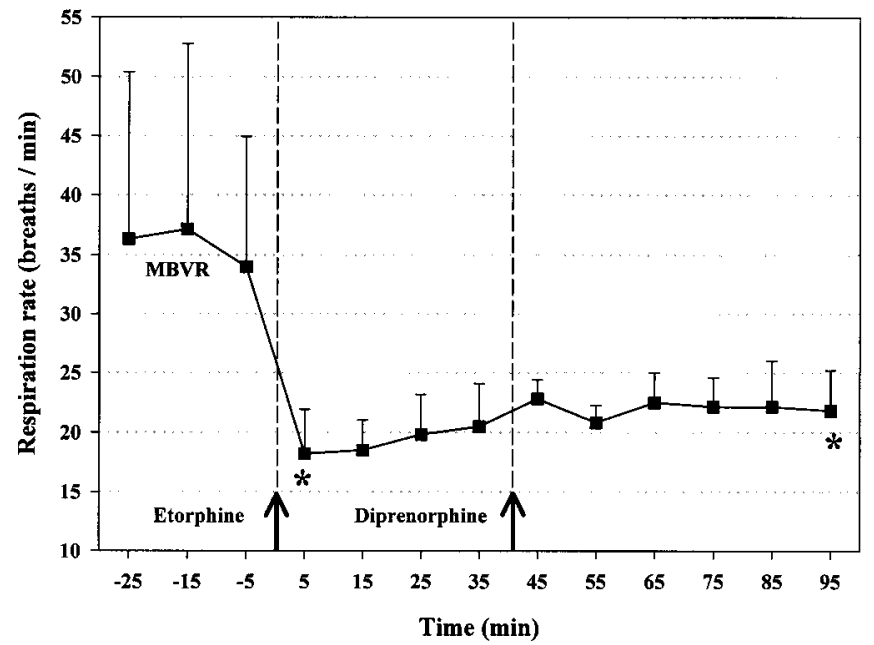

Fig. 4: Mean respiratory rate in goats treated with etorphine. Error bar $=1 \mathrm{SE} . \mathrm{MBVR}=$ mean baseline value at rest. Asterisks indicate statistically significant differences $(P \leq 0.05)$ between MBVR and the signalled mean value. Arrows indicate times at which etorphine and diprenorphine were injected.

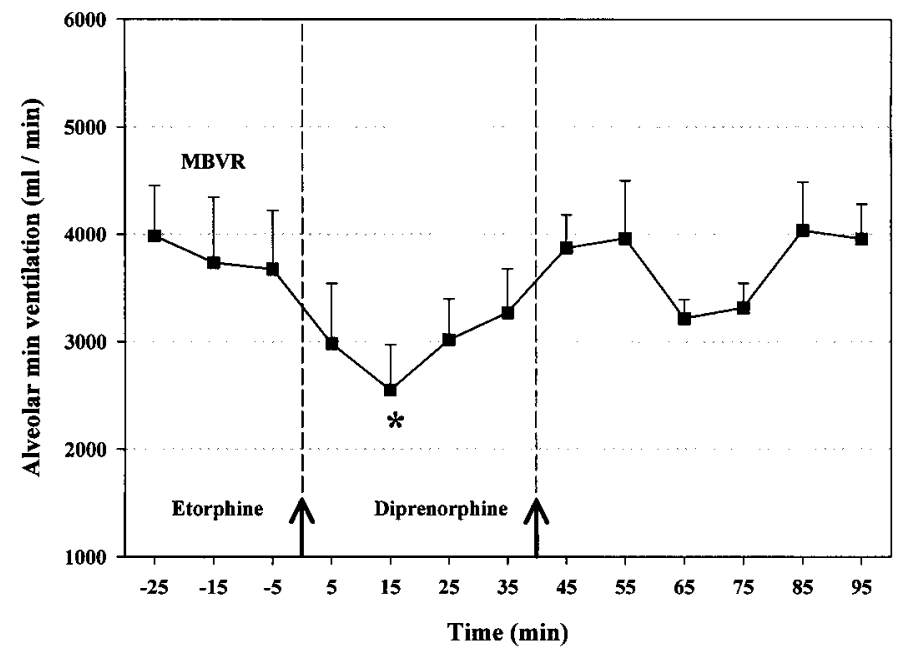

Fig. 5: Mean alveolar minute ventilation in goats treated with etorphine. Error bar $=1 \mathrm{SE}$. MBVR = mean baseline value at rest. The asterisks indicates a statistically significant difference $(P \leq 0.05)$ between MBVR and the signalled mean value. Arrows indicate times at which etorphine and diprenorphine were injected.

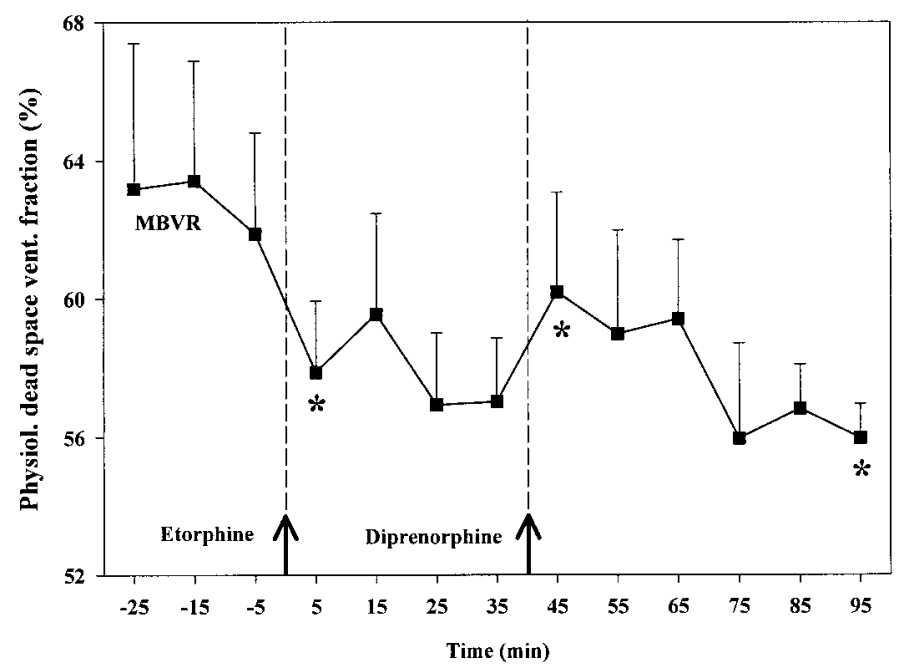

Fig. 6: Mean physiological dead space ventilation fraction in goats treated with etorphine. Error bar $=1 \mathrm{SE}$. MBVR = mean baseline value at rest. Asterisks indicate statistically significant differences $(P \leq 0.05)$ between MBVR and the signalled mean value. Arrows indicate times at which etorphine and diprenorphine were injected. bilised goats was followed by gradual recovery. This improvement in respiratory function may have resulted from the hypoxic stimulation of the chemoreceptors that are reported to remain effective even when opioids have suppressed theresponsiveness of therespiratory centre to carbon dioxide ${ }^{22}$. Although stimulation of respiration by the peripheral chemoreceptors is reported to be come marked only at a $\mathrm{PaO}_{2}$ of between 2.7 to $5.3 \mathrm{KPa}$ in humans ${ }^{8}$ and below $8.0 \mathrm{KPa}$ in horses $^{17}$, it appears that this stimulus may bemoresignificant in goats. It has been shown that denervation of the carotid body in goats results in some hypoventilation, hypoxaemia and hypercapnoea ${ }^{17}$. In addition to these changes, it is likely that reduction of the pharmacodynamic effects of etorphine as a result of its metabolismalso permitted improvement in respiratory function over time.

The onset of the effects of etorphine in wildlife is reported to take place 2-8 minutes after intramuscular administration. The peak effects, depending on therateof absorption, follow in 15-30 minutes. The duration of effect is approximately 1 hour ${ }^{26}$. In goats, Heard et al ${ }^{11}$ reported that $0.02 \mathrm{mg} / \mathrm{kg}$ of etorphine administered intravenously resulted in a maximum depression of respiratory rate within 2.5 minutes. The respiratory rate then gradually returned to within normal limits by 45 minutes PDA.

The decrease in physiological dead space ventilation following the administration of etorphine was an unexpected finding. Although the cause of this decrease cannot be determined from the results of this trial, some possible causes can besuggested. Theseincludea decrease in alveolar dead space due to improved alveolar perfusion. Etorphine is reported to increase systemic mean arterial blood pressure owing to centrally-mediated activation of sympathetic tone $e^{24}$. It may also result in increases in pulmonary arterial pressure. A second possible cause is hypoventilation (Fig. 3) induced by administration of etorphine. Hypoventilation is reported to result in a reduction in the functional anatomical dead space in humans, owing firstly to a more streamlined or laminar flow of gas through the bronchi, and secondly to mixing of all gases lying below the carina by the heartbeat ${ }^{20}$. Thirdly, less inspired air is delivered to alveoli with minimal circulation as a result of a slower respiration rate and, therefore, an increased duration of inspiration ${ }^{19}$.

Diprenorphine administered intravenously is reported to antagonise the effects of etorphine rapidly ${ }^{1}$. In this study it was not possible to determine to what 
degree it reversed the respiratory depressant effects of etorphine, as there was a gradual recovery of respiratory function and the $\mathrm{PaCO}_{2}$ had returned to its base line value by the time the diprenorphine wasadministered. The continued depression of the respiratory rate following the administration of the diprenorphine (Fig. 4) was possibly due to the fact that diprenorphine is a mixed opioid antagonist, retaining some agonist activity ${ }^{26}$. It is also possible that the low respiratory rate may have been caused by residual etorphine activity.

\section{CONCLUSIONS}

Goats proved to be suitable animals in which to determine the physiological changes that occur in respiratory function following the administration of etorphine. They were amenable to being handled while restrained on the research table and rapidly became habituated to and tolerant of the experimental proce dures. It is considered that any adrenergic response in the goats before administration of etorphine was effectively minimised. Following each trial, the goats rapidly recovered without significant side-effects.

The administration of etorphine to the goats resulted in respiratory depression as reported in various other immobilised animal species ${ }^{9,26}$. The decrease was due primarily to a slowing of respiratory rate, rather than a reduction in tidal volume. Changes to the percentage physiological shunt and dead space ventilation do not appear to contribute significantly to the decrease in $\mathrm{PaO}_{2}$ and increase in $\mathrm{PaCO}_{2}$ induced by theintramuscular administration of etorphine.

It was not possible to determine how effective diprenorphine was in reversing the depressant effects of etorphine on respiratory function.

\section{ACKNOWLEDGEMENTS}

Funding for this study was provided by the Faculty of Veterinary Science of the University of Pretoria. We gratefully acknowledge this support, and Prof. H T Groeneveld of the Department of Statistics and Dr M J van der Linde at the Research Division, University of Pretoria, for their expert assistance and analysis of data. Weal so thank the National Zoological Gardens, Pretoria for providing accommodation and feed for the goats, and Dr I Espie, Sister J Kingsley and Ms K Labuschagne for their assistance during the training of the goats and the running of the trials. We would like to express our appreciation to DrF Chaparro, Director of the Pretoria Biomedical Research Centre for his personal support and assistance, and for the donation of facilities and equipment. The professional and technical support from members of staff was greatly appreciated.

\section{REFERENCES}

1. Alford B T, Burkhart R L, Johnson W P 1974 Etorphine and diprenorphine as immobilizing and reversing agents in captive and free-ranging mammals. Journal of the A merican Veterinary Medical Association 164: 702-705

2. BlaneG F, BouraA L A, Fitzgerald A E, Lister R E 1967 Actions of etorphine hydrochloride, (M99): a potent morphine-like agent. British Journal of Pharmacology and Chemotherapy 30: 11-22

3. Booth N H 1988 Neuroleptanalgesics, narcotic analgesics, and analgesic antagonists. In McDonald L E, Booth N H (eds) $V$ eterinary pharmacology and therapeutics. IowaStateUniversity Press, Ames: 290-328

4. Branson K R, Gross M E, Booth N H 1995 O pioid agonists and antagonists. In Adams H R (ed.) Veterinary pharmacology and therapeutics. Iowa State University Press, Ames: 274-310

5. Butler H C 1962 Subcutaneous relocation of the carotid artery for experimental purposes. A merican Journal of Veterinary R esearch 23: 165-165

6. Cheney C S, Hattingh J 1988 Effects of chemical immobilisation on the blood composition of impala A epyceros melampus (Lichtenstein). Journal of the South African Veterinary Association 59: 13-18

7. Guyton A C 1986 Pulmonary ventilation. In Dreibel bisD (ed.) Textbook of medical physiology. WB Saunders, Philadelphia: 466-48

8. Guyton A C 1986 Regulation of respiration. In DreibelbisD (ed.) Textbook of medical physiology. WBSaunders, Philadel phia: 504-505

9. Haigh J C 1982 Mammalian immobilizing drugs, their pharmacology and effects. In Nielsen L, Haigh J C, Fowler M E (eds) Chemical immobilization of $\mathrm{N}$ orth American wildlife. Wisconsin Humane Society, Milwaukee: 46-62

10. Haigh J C 1990 Opioids in zoological medicine. A review. Journal of Z0o and Wildlife M edicine 21: 391-413

11. Heard D J, Kollias G V, Buss D, Caligiuri R, Coniglario J 1990 Comparative cardiovascular effects of intravenous etorphine and carfentanil in domestic goats. Journal of $Z 00$ and Wild life M edicine 21: 166-170

12. Heard D J, NicholsW W, Buss D, Kollias G V 1996Comparativecardiopulmonary effects of intramuscularly administered etorphine and carfentanil in goats. A merican Journal of Veterinary Research 57: 87-96

13. Jaffe J H, Martin W R 19900 pioid analgesics and antagonists. In Gilman A G, Rall T H, Nies A S, Taylor P (eds) Goodman and Gillman's The pharmacological basis of therapeutics. Pergamon Press, New York: 485-521

14. Jansen D L, Swan G E, Raath J P, M James S W, Allen J L, De Vos V, Williams K E 1993 Immobilization and physiological effects of the narcotic A-3080 in impala (A epyceros melampus). Journal of Z 00 and Wildlife M edicine 24: 11-18

15. Lavoie J P, Pascoe J R, Kurpershoek CJ 1992 Effect of head and neck position on respira- tory mechanics in horses sedated with xylazine. American Journal of Veterinary Research 53: 1652-1657

16. Lees P 1991 Sedatives, anticonvulsants, central muscle relaxants and analgesics. In Brander G C, Pugh D M, Bywater R J, Jenkins W L (eds) Veterinary applied pharmacology and therapeutics. Baillière Tindall, London: 328-354

17. McDonell W 1996 Respiratory system. In Thurmon J C, Tranquilli W J, Benson G J (eds) Lumb and Jones's veterinary anesthesia. Williams \& Wilkins, Baltimore: 115-147

18. McKean T A, Stock M, Magonigle B 1978 Theeffect of immobilization with M-99plus acepromazine on physiological parameters of domesticgoats. Journal of WildlifeM anagement 42: 176-179

19. Nunn J F 1972 Mechanisms of pulmonary ventilation. In A pplied respiratory physiology with special reference to anaesthesia. Butterworths, London: 112-143

20. Nunn J F 1972 Respiratory dead space and distribution of the inspired gas. In A pplied respiratory physiology with special reference to an aesthesia. Butterworths, London: 177-208

21. Pearce P C, Kock R A 1989 Physiological effects of etorphine, acepromazine and xylazine in the scimitar horned oryx (0 ryx dammah). Research in Veterinary Science 47: 78-83

22. Reisine T, Pasternak G 1996 Opioid analgesics and antagonists. In Hardman J G, Limbird L E, Molinoff $P$ B, Ruddon R W, Gilman A G (eds) Goodman \& Gilman's The pharmacological basis of therapeutics. McGraw-Hill, New York: 521-555

23. Riedesel D H 1996Drugs acting on thecentral nervous system. In Ahrens F A (ed.) Pharmacology. Williams \& Wilkins, Baltimore: 61-80

24. RoquebertJ, Delgoulet C 1988Cardiovascular effects of etorphine in rats. Journal of Autonomic Pharmacology 8: 39-43

25. Steffy EP 1986 Somecharacteristics of ruminants and swine that complicate management of general anesthesia. Veterinary Clinics of N orth A merica: Food A nimal Practice 2: 507-516

26. Swan G E 1993Drugs used for the immobilization, capture and translocation of wild animals. In McKenzie A A (ed.) The capture and care manual. Wildlife Decision Support Services and the South African Veterinary Foundation, Pretoria: 2-64

27. Thurmon J C, Nelson D R, Kumar A 1974 Etorphine and triflupromazine as immobilizing agentsin the goat. Journal of the A merican Veterinary Medical Association 165: 168-171

28. Watney G C G 1993Algorithms for calculating between blood oxygen saturation and oxygen tension in some mammals. Journal of Veterinary A naesthesia 20: 14-17

29. West J B 1985 Ventilation-perfusion relationships. In Tracy T M (ed.) Respiratory physiology - the essentials. Williams \& Wilkins, Baltimore: 49-66

30. West J B 1987 Appendix. In Pulmonary pathophysiology - the essentials. Williams \& Wilkins, Baltimore: 203-205

31. West J B 1987 Gas exchange. In Pulmonary pathophysiology - the essentials. Williams \& Wilkins, Baltimore: 19-41

32. West J B 1995 Ventilation. In Respiratory physiology - the essentials. Williams \& Wilkins, Baltimore: 11-20 